\title{
1 Behavioral responses to injury and death in wild Barbary macaques (Macaca sylvanus)
}

2 Liz AD Campbell*1 ${ }^{1}$, Patrick J Tkaczynski*2 ${ }^{2}$, Mohamed Mouna ${ }^{3}$, Mohamed Qarro ${ }^{4}$, James

3 Waterman $^{1}$, Bonaventura Majolo ${ }^{1}$

4

$5 *$ Contributed equally as lead authors.

$6{ }^{1}$ School of Psychology, University of Lincoln, UK

$7 \quad{ }^{2}$ Centre for Research in Evolutionary and Environmental Anthropology, Department of Life

8 Sciences, University of Roehampton, London, UK

$9 \quad{ }^{3}$ Mohammed V University, Institut Scientifique, Rabat, Morocco

$10{ }^{4}$ Ecole Nationale Forestiére d’Ingenieurs, Tabriquet Salé, Morocco

11

12 Correspondence to:

13 Patrick Tkaczynski

14 Department of Life Sciences

15 University of Roehampton

16 London, SW15 4JD

17 UK

email: tkaczynp1@ @roehampton.ac.uk 
The wounding or death of a conspecific has been shown to elicit varied behavioral responses throughout thanatology. Recently, a number of reports have presented contentious evidence of epimeletic behavior towards the dying and dead among non-human animals, a behavioral trait previously considered uniquely human. Here, we report on the behavioral responses of Barbary macaques, a social, non-human primate, to the deaths of four group members (one high-ranking adult female, one high-ranking adult male, one juvenile male and one female infant), all caused by road traffic accidents. Responses appeared to vary based on the nature of the death (protracted or instant) and the age class of the deceased. Responses included several behaviors with potential adaptive explanations or consequences. These included exploration, caretaking (guarding, carrying, and grooming) and proximity to wounded individuals or corpses, and immediate as well as longer-lasting distress behaviors from other group members following death, all of which have been reported in other non-human primate species. These observations add to a growing body of comparative evolutionary analysis of primate thanatology and help to highlight the multifaceted impacts of human-induced fatalities on an endangered and socially complex primate.

KEYWORDS: Thanatology $\cdot$ Barbary macaque $\cdot$ Epimeletic behavior

\section{Introduction}

Responses to dying and dead conspecifics have been documented in several nonhuman primates, ranging from cannibalism (orangutans [Pongo abelii], Dellatore et al, 2009), to curiosity and exploration (snub-nosed monkey [Rhinopithecus bieti], Li et al, 2012; chimpanzees [Pan troglodytes], Biro et al, 2010), to putative compassion and caretaking (e.g. chimpanzees, Anderson et al, 2010; Biro et al, 2010, Cronin et al, 2011; common marmosets [Callithrix jacchus], Bezerra et al, 2014), and group distress (chimpanzees, Boesch 1991; Anderson et al, 2010). Epimeletic behavior, i.e., care or apparent altruism to the dying or 
dead, is widely considered uniquely human (Counts and Counts, 1991), and certain reports have contended that it is absent in non-human primate species such as geladas (Theropithecus gelada; Fashing et al, 2011), and individual chimpanzee populations (Stewart et al, 2012).

However, reports of apparent epilemetic behavior from other taxonomic groups (e.g African elephants [Loxodonta africana], Douglas-Hamilton et al, 2006; river otters [Pteronura brasiliensis], Davenport, 2010; long-beaked common dolphins, [Delphinus capensis], Park et al, 2013), in addition to the aforementioned examples in non-human primates, have provoked calls for developing a comparative evolutionary approach towards animal thanatology and compassionate behavior in particular (Anderson, 2011; Fashing and Nyugen, 2011). Variation in responses to the dying and dead may be related to inter-species behavioral differences, inter-individual variation in the experience of observing death, or a reflection of varying strengths of social ties with the deceased (Appleby et al, 2013; Bercovitch, 2012; Stewart et al, 2012). Due to intensive infant-rearing in mammals, especially by females (Hirshfield and Tinkle, 1977), the death of an infant is likely to have notable physical and psychological impacts (Majolo and McFarland, 2009). Unsurprisingly then, animal thanatology literature, particularly for non-human primates, is largely dominated by analyses of conspecific responses to infant death (Sugiyama et al, 2009). The most frequently reported response to infant death is the continued carrying of the infant corpse, which has been documented in a range of primate species including Japanese macaques (Macaca fuscata; Sugiyama et al, 2009), chimpanzees (Biro et al, 2010; Cronin et al, 2011), gorillas (Gorilla beringei; Warren and Williamson, 2004) and Barbary macaques (Macaca sylvanus). Barbary macaque mothers have been observed to carry their dead infants (Campbell, pers. obs.), while males have been reported to continue using infant corpses in "agonistic buffering" with other males (Merz, 1978). Females have also been observed to 
increase self-suckling following the death of their infants, possibly as a means of stress relief (Majolo and McFarland, 2009).

Less frequently observed and reported, particularly in the wild, are the reactions and responses of non-human primates to dying or dead conspecifics of other age-classes. Such information could be particularly informative with respect to how variation in social ties may reflect variation in responses to death (Buhl et al, 2012). Here, we report on the deaths of four Barbary macaques of differing sex- and age-classes resulting from impact with road vehicles. In two cases, the monkeys were mortally wounded and the death protracted, while in the two other cases, death was instant. Supported by photographic and video evidence, we describe behavioral responses to these events and highlight differences in response according to the nature of the death and the age-class of the deceased.

\section{Methods}

Observations were made at a study site located in the oak and cedar forest near the city of Azrou, Morocco ( $33^{\circ} 24^{\prime} \mathrm{N}$ to $05^{\circ} 12^{\prime} \mathrm{W}$; elevation 1,500-2,000 $\mathrm{m}$ above sea level). This area is located within the Ifrane National Park, in the Middle Atlas Mountains. Barbary macaques are an endangered species (IUCN, 2012) and this region contains the largest remaining population of the species (van Lavierien and Wich, 2010). Barbary macaques live in multimale, multi-female, female-bonded groups and have been shown to form long-term intra- and inter-sex relationships with conspecifics (Fooden, 2007; Young et al, 2014). The group of macaques in this report (the Blue group) has been habituated and studied since January 2013. All deaths occurred at a tourist picnicking site which the group frequently visits. Prior to the deaths reported here, the group consisted of approximately 34 individuals: eight adult males, seven adult females, one sub-adult male, one sub-adult female, approximately thirteen juveniles (as juveniles have not been individually identified for study, this number is an 
estimate based on an initial census) and four infants. The four reported deaths occurred between September 2013 and October 2014. Data from focal samples and ad libitum scan samples (Altmann, 1974) were used to calculate dominance hierarchies prior to the first reported death (calculated from four months of behavioral data; May-September 2013). David's score calculations (David, 1987) were used to determine the hierarchies, an approach which has previously been applied in this species (e.g. Kaburu et al, 2012; see supplementary materials for details). Observations of responses to deaths were recorded using focal and $a d$ libitum sampling of all individuals which approached within $15 \mathrm{~m}$ of the injured or dead individual (Altmann, 1974). Behaviors recorded included all orientation toward, approaches toward, and any social interactions with the injured or dead individual, as well as anxietyrelated behaviours (scratching, yawning). In addition to these field notes, for two of the observations, responses to the deaths were video recorded using a Sony Handycam DCRSX33. For the other observations, only photographic evidence was collected.

\section{Results}

\section{Dominance hierarchy}

A significant linear hierarchy was found in both males $(r=0.90 ; p<0.00 ; n=9)$ and females $(\mathrm{r}=0.97 ; \mathrm{p}<0.00 ; \mathrm{n}=7)$.

\section{Observation 1: Protracted death of high-ranking female}

The highest-ranked cycling female of the group, MA, was hit by a bus when crossing a road at approximately 15:00 on 27/09/2013. Visible injuries included partial detachment of one leg and a large laceration of her anogenital swelling. MA was able to climb into a tree, approximately $10 \mathrm{~m}$ above the ground. Two adult males (RG and IS) climbed the tree and approached her, teeth-chattering and lip-smacking; behaviors associated with reassurance and 
reconciliation. Both monkeys were observed delicately touching and inspecting the wounds.

As the other group members left the tourist site to go into the forest to sleep they made several "long-calls", presumably to MA, from approximately 100 m away; such calls are usually used when an individual is separated from the group or the group is searching for a separated individual. MA vocalised back but was unable to move to join them. Subsequently, the group began to make fear screams and grimacing facial displays. The group, now including IS and RG, then left to sleep approximately $500 \mathrm{~m}$ from MA. Approximately one hour after the group left, RG returned to MA. They teeth-chattered at one another, he touched her injured leg several times, including prolonged body contact between his hand and her return of RG, several more males returned from the forest (IS, RO, GU) and sat below the tree MA was in, with some climbing up sit beside her. As it became dark (c.19:00), all males eventually left MA to join the rest of the group at their sleeping site. An hour after dark, IS returned and sat in an adjacent tree to MA, where he remained until the observers left for the night (c.22:00).

When observers returned at approximately 05:00, MA's corpse was discovered unmoved from the tree in which she was previously observed. IS was found in the same adjacent tree as he had been seen in the night before. It is assumed IS remained with MA when she died during the night. At c.06:30, IS crossed the canopy to approach MA's corpse. He touched her body twice, before moving back to the tree he had been in before, where he remained for the following eight hours, until 15:41, when he left the tree to feed for the first time that day. The rest of the group returned to the vicinity of MA's corpse at c.09:35. Table 1 in the supplementary material provides a detailed timeline of group members' responses to MA's corpse. Males showed the strongest behavioral response. Three males (GU, TI and FE) 
entered the tree she was in, spending an average of 18:09 $( \pm 10: 29)$ minutes in the tree with her. One male (TI) approached within $1 \mathrm{~m}$ of the body, displaying 5 anxiety-related behaviors (scratching and yawning) and six exploratory/vigilance behaviors (head-bobbing). Two (of six) adult females (SA and WA) passed the tree without showing any reaction, while two others (IZ and EL) were not seen near the body. The two remaining females (CO and PE) spent a short amount of time within $10 \mathrm{~m}$ of the body (average 2:28 minutes) during which they watched the body and exhibited one anxiety-related behavior (scratching) and three exploratory/vigilance behaviors (glance and head-bobs). One sub-adult female (NI) spent more than 20 minutes within $1 \mathrm{~m}$ of the body, head-bobbing at her four times, grooming herself for 2:44 minutes, and grooming the body for 14:00 minutes (video 1 in supplementary material). Three juveniles entered the tree MA's body was in and remained for approximately one minute, spending the entire time watching her. At approximately 17:00 when the group had begun to move away from the tourist site, and 19 hours since MA was last seen alive, local merchants removed the corpse from the tree for burial as it posed a danger to visiting for burial.

\section{Observation 2: Immediate death of alpha male}

FE, the highest-ranking male in the group, was killed on 31/10/13 at 12:20 following a collision with a vehicle on a road. He died instantly and there were few signs of external damage or wounds. When local merchants removed the corpse to avoid conflict between the monkeys and feral dogs, at least three adults within the group screamed at the merchants, while at least three juveniles and a sub-adult female (UR) observed the body from trees above. Due to crowding over the corpse by tourists and the initial vocal reaction of the 
monkeys, FE was swiftly taken to be buried. UR and approximately three juveniles followed the sellers to the burial site, an open area the monkeys had never before been observed to use, and watched silently from a distance as the body was buried. They returned to the group several minutes after the burial. No adult monkeys were observed near the site during this burial.

\section{Observation 3: Immediate death of juvenile}

On 19/05/14 at 14:00, a male juvenile (between 2-3 years old) was struck by a vehicle and instantly killed (struck in the head, one eye hanging out and jaw dislocated). The body was moved off the road by local merchants immediately following the collision. The group screamed and became extremely agitated, causing the merchants to abandon the corpse. One adult male, CA, took the corpse up a tree (figure 2). CA remained with the juvenile's corpse for over 30 minutes, before eventually dropping it to the ground. UR (sub-adult female) spent several minutes with the body on the ground. The body was guarded by group members (including CA and another adult male, GU) for approximately 80 minutes after the accident, including threatening and charging a park official who attempted to get close to the body. After the group moved away from the corpse and left the area, local merchants removed the corpse for burial. CA and GU followed the merchants and corpse to the burial site (the area used to bury FE described previously). During the burial, adult male monkeys threatened and vocalised at the merchants. CA was at the forefront of the group, approaching as close as $5 \mathrm{~m}$ to the merchants and threatening them. One unidentified male, the lowest-ranking female (PE) and approximately three juveniles joined them at the burial site (figure 3). Many performed aggressive calls and threats. Due to the clear agitation of the monkeys and the potential risk of aggression from the group, particularly from CA, the burial was abandoned and all human observers moved away from the corpse. CA moved immediately to sit near the 
body and remained in this area with at least one other juvenile for two hours before they eventually departed and the body could be buried.

\section{Observation 4: Protracted death of infant}

On 24/10/14 at 12:03, WE, the approximately 4-month-old infant of the female WA, was hit by an automobile, partially severing one leg. WA immediately carried WE, still alive at this point, into a tree and began grooming her. A sub-adult male (ME) approached the pair and teeth-chattered at them. At 12:25, while adjusting position within the tree, WE fell around 3 $\mathrm{m}$ to the ground. WA climbed down from the tree and dragged WE approximately $5 \mathrm{~m}$, but she was displaced from WE by the presence of merchants, tourists and dogs. WE continued to struggle on the ground, crawling on her arms, but succumbed to her injuries at 12:33.

Table 2 in the supplementary material provides a detailed timeline of group members' responses to WE's corpse. After WE's death, WA climbed down from the tree and inspected the body, but was disturbed by a local merchant who came close to determine if the infant had died. WA threatened the merchant and retreated into a tree. When the merchant left, WA descended, inspected and lifted the corpse before carrying it approximately $10 \mathrm{~m}$ to the other side of the road (see video 2 in supplementary material). She then moved several metres away to feed on bread distributed by tourists. At 12:47, feral dogs approached the corpse; WA alarm barked and threatened the dogs, which left after several minutes. Over the next hour, WA engaged in extensive bouts of self-grooming in a tree above WE's corpse, occasionally making distress/fear screams (see video 3 in supplementary materials). At 14:30, WA left the tree and the corpse. At 14:35, after the whole group had moved more than $100 \mathrm{~m}$ away from the corpse and were leaving the tourist site, a local merchant took the corpse for burial. Many members of the group rushed back to the merchant carrying the corpse and performed several threatening behaviors (bared teeth, ground slaps, growling etc.). At the forefront of the group 
were WA, two adult males (GU and IS) and another adult female (IZ). The monkeys reacted thus for around 30 seconds, until the merchant was out of sight, after which they moved away from the tourist site. No monkeys followed the merchant to the burial site. For the remainder of the day, WA was observed intermittently (approximately every 30 minutes) making distress/fear screams and displaying vigilance/searching behavior. At c.16:00, WA left the group to return in the direction of the tourist site and stayed $75 \mathrm{~m}$ from the tourist site $(100 \mathrm{~m}$ from the rest of the group) for approximately 45 minutes, continuing to display vigilance/searching behavior, before returning to the group. The next day, she sporadically made distress vocalisations and was often seen away from the group.

\section{Discussion}

This report presents the behavioral responses of conspecific group members to the mortal wounding and death of four wild Barbary macaques. In these accounts, several behaviors directed to the dying and dead are reported which are similar to those seen in other mammals, especially non-human primates; namely exploration (sniffing and touching of wounds or corpses, Buhl et al, 2012) and caretaking behaviors, including guarding (Boesch 1991), carrying (Fashing et al, 2011), and grooming of corpses (Boesch 1991).

Affiliative behaviors resembling epimeletic behavior were shown in both cases where death was protracted. Prior to death, MA was attended by males which examined her wounds, displayed mollifying facial displays (lipsmacks and teeth-chattering), and groomed her. When WE was wounded, her mother carried and groomed her, and both the mother and infant received affiliative teeth-chattering from a sub-adult male of the group. These behaviors are similar to those observed in chimpanzees (Anderson et al, 2010) and more recently in common marmosets (Bezerra et al, 2014), where individuals were attentive and affiliative to dying conspecifics. In the cases presented here, some affiliative behaviors continued post- 
mortem. Grooming of corpses has been witnessed in a number of non-human primates, typically with deceased infants (Boesch 1991; Anderson et al, 2010; Biro et al, 2010; Cronin et al, 2011; Fashing et al, 2011; Li et al, 2012; Buhl et al, 2012). Explorative or curiosity behaviors towards the body of the dead conspecifics have been recorded in other non-human primate species (Biro et al, 2010; Fashing et al, 2011; Cronin et al, 2011) and appears to be a common reaction in the majority of reported animal thanatology (Bercovitch, 2012). Such responses have been suggested to reflect a cognitive inability of the animal to "understand" death. Alternatively, they may reflect an adaptive "wait and see" strategy whereby conspecifics are unsure of the state of the injured, diseased or deceased, requiring time to make an accurate assessment of whether to abandon their stricken group member; this strategy could have long-term advantages if individuals sometimes recover (Hrdy, 1999; Sugiyama et al, 2009; Li et al, 2012; Appleby et al, 2013). Additionally, these behaviors may present a learning opportunity, helping individuals to avoid a cause of death or injury if similar conditions are encountered again (Cronin et al, 2011).

In all four cases reported here, other group-members screamed, threatened, and charged when humans or feral dogs approached or moved the body. They also followed merchants to the burial site. Guarding of corpses has been reported in, among others, chimpanzees (Boesch 1991), rhesus macaques (Macaca mulatta, Buhl et al, 2012) and common marmosets (Bezerra et al, 2014). The male IS remained with MA overnight, recalling the all-night attendance following a female chimpanzee's death reported by Anderson et al (2010). Unlike other non-human primate examples of motherly reactions to infant death (Biro et al, 2010; Fashing et al, 2011; Li et al, 2012), WA carried her deceased infant only for a short period of time, although this may be a consequence of the highly disturbed environment at the tourist site (including feral dogs, local merchants, and tourists). In line with the aforementioned "wait and see" strategy, guarding and/or carrying of corpses 
could be advantageous if individuals sometimes recover or by preventing predation (Hrdy, 1999; Sugiyama et al, 2009). Violent deaths with graphic injuries may also cause heightened behavioral and physiological stimulation, leading to increased guarding and aggression (Buhl et al, 2012). These responses can be maladaptive; for example, when mothers carry dead infants, the cost is predominantly energetic (Sugiyama et al, 2009). We also observed instances of individuals separating themselves from the group or placing themselves at risk by guarding corpses in close proximity to humans and feral dogs.

The injury and death of the high-ranking female, MA and the death of the juvenile, invoked strong, nearly group-wide responses, with males showing particularly strong reactions in both cases. In contrast, responses to the death of the alpha male FE and the infant WE were limited to a few individuals. The strength of social ties between the surviving and deceased has been proposed to explain the variation in the strength of responses to a death (Appleby et al, 2013; Bercovitch, 2012; Stewart et al, 2012) and possibly to injury as well. In female-bonded groups, dominance and kinship are expected to predict the strength of female social bonds (Johnson et al, 2014), while Barbary macaque males are known to invest time and effort in forming social bonds with infants and juveniles through playing and grooming (Deag, 1980; Small, 1990) and have recently been shown to form stable social bonds with other adult males (Young et al, 2014). The protracted nature of MA's injury and death may have allowed more opportunity for reactions from other group members. Strong social bonds and paternal care may explain the sustained defense of the juvenile corpse, particularly by males. It is also possible that the very graphic nature of MA's and the juvenile's injuries evoked a strong response among group members (Buhl et al, 2012). The comparatively subdued behavioral response to the alpha male's (FE) death may be a consequence of weak social ties, or may simply have been due to the relatively quick removal of the corpse and the proximity of local merchants and tourists. The injury and death of the infant WE produced 
notable responses only from the mother and a sub-adult male, though the moving of her corpse elicited strong aggressive responses from several adults in the group, both males and females. As a 4-month-old infant of a low-ranking female, it is possible that WE had not yet formed any strong relationship in the group other than with her mother. Concurrently, the mother's low rank may reduce the likelihood of other group members, particularly females, investing in the protection of her infant.

In all cases, the injury and death of a group member caused observable distress to other monkeys, including vocalisations, agitation, and anxiety-related behaviors. Similar responses have been reported in chimpanzees following the death of a group member (Boesch 1991; Anderson et al, 2010). Aside from these immediate reactions, there were also obvious longer-lasting effects of these deaths on some individuals, including prolonged distress behaviors, separation from the group, and behavioral inactivity. In the case of WA, distress behaviors (vocalisations and searching behaviors) were displayed long after the burial of her infant, and continued the following day. Our report outlines the complex behavioral responses of Barbary macaques to dying and deceased conspecifics, adding to our understanding of both Barbary macaque sociality and more broadly, animal thanatology.

\section{Acknowledgements}

We thank Ifrane National Park, the Haut Commissariat aux Eaux et Forêts et à la Lutte Contre la Désertification, Ecole Nationale Forestiere d'Ingeniuers and Institut Scientifique de Rabat for research permission and facilitation. We thank Melanie LaCava, Kevin Remeuf, Selma El Fassi-Fihri and Els van Laverien for their contribution to incident reporting, photography and filming. We thank Alice Marks and Selma El Fassi-Fihri for efforts collecting data on the dominance hierarchies. Finally, we thank Dr Caroline Ross, Dr 
Julia Lehmann and Prof Ann MacLarnon for their comments in the writing of this manuscript.

\section{References}

Altmann J (1974) Observational study of behavior: sampling methods. Behaviour 49:227-267.

Anderson JR, Gillies A, Lock LC (2010) Pan thanatology. Curr Biol 20:R349-R351.

Anderson JR (2011) A primatological perspective on death. Am J Primatol 73:410414.

Appleby R, Smith B, Jones D (2013) Observations of a free-ranging adult female dingo (Canis dingo) and litter mates' responses to the death of a pup. Behav Process 96:4246.

Bercovitch FB (2012) Giraffe cow reaction to the death of her newborn calf. Afr J Ecol 51:376-379.

Bezerra BM, Keasey MP, Schiel N, da Silva Souto A (2014) Responses towards a dying adult group member in a New World monkey. Primates 55:185-188.

Biro D, Humle T, Koops K, Sousa C, Hayashi M, Matsuzawa T (2010) Chimpanzee mothers at Bossou, Guinea carry the mummified remains of their dead infants. Curr Biol 20:R351-R352.

Boesch C (1991) The effects of leopard predation on grouping patterns in forest chimpanzees. Behavior 117:220-242.

Buhl JS, Aure B, Ruiz-Lambides A, Gonzalez-Martinez J, Platt ML, Brent LJN (2012) Response of Rhesus macaques (Macaca mulatta) to the body of a group member that died from a fatal attack. Int J Primatol 33:860-871. 
Cronin KA, van Leeuwen EJC, Mulenga IC, Bodamer MD (2011) Behavioral response of a chimpanzee mother toward her dead infant. Int J Primatol 73:415-421.

Counts DR, Counts DA (1991) Coping with the Final Tragedy: Cultural Variation in Dying and Grieving. Baywood Publishing Company Inc, Amityville, NY. utans. Primates 50:277-281.

Davenport LC (2010) Aid to a declining matriarch in the Giant Otter (Pteronura brasiliensis). PLoS ONE 5(6): e11385. doi:10.1371/journal.pone.0011385.

Dellatore DF, Waitt CD, Foitova I (2009) Two cases of mother-infant cannibalism orang-

David, HA (1987) Ranking from unbalanced paired-comparison data. Biometrika 74:432-436.

Deag JM (1980) Interactions between males and unweaned Barbary macaques: Testing the agonistic buffering hypothesis. Behaviour 75:54-80.

Douglas-Hamilton I, Bhalla S, Wittemyer G, Vollrath F (2006) Behavioural reactions of elephants towards a dying and deceased matriarch. Appl Anim Behav Sci 100:87102.

Fashing PJ, Nguyen N (2011) Behavior toward the dying, diseased, or disabled among animals and its relevance to paleopathology. Int J Paleopathol 1: $128-129$.

Fashing PJ, Nguyen N, Barry TS, Goodale CB, Burke RJ, Jones SC, Kerby JT, Lee LM, Nurmi NO, Venkataraman VV (2011) Death among geladas (Theropithecus gelada): a broader perspective on mummified infants and primate thanatology. Am J Primatol 73:405-409.

Fooden J (2007) Systematic Review of the Barbary Macaque, Macaca Sylvanus (Linnaeus, 1758). Fieldiana Zool 113:1-60.

Hirshfield MF, Tinkle DW (1975) Natural selection and the evolution of reproductive 
Hrdy SB (1999) Mother Nature: A History of Mothers, Infants and Natural Selection. Pantheon Books, New York, 752 pp.

Johnson ET, Snyder-Mackler N, Beehner JC, Bergman TJ (2014) Kinship and dominance rank influence the strength of social bonds in female geladas (Theropithecus gelada).

Kaburu SK, MacLarnon A, Majolo B, Qarro M, Semple S (2012) Dominance rank and self-scratching among wild female Barbary macaques (Macaca sylvanus). Afr Zool 47: 74-79.

Li T, Ren B, Li D, Zhang Y, Li M (2012) Maternal responses to dead infants in Yunnan snub-nosed monkey (Rhinopithecus bieti) in the Baimaxueshan Nature Reserve, Yunnan, China. Primates 53:127-32.

Majolo B, McFarland R (2009) Self-suckling in Barbary macaque (Macaca sylvanus) mothers before and after the death of their infant. Am J Primatol 140: 381-383.

Merz E (1978) Male-male interactions with dead infants in Macaca sylvanus. Primates 19:749-754.

Park KJ, Sohn H, An YR, Moon DY, Choi SG, An DH (2013) An unusual case of caregiving behavior in wild long-beaked common dolphins (Delphinus capensis) in the East Sea. Mar Mam Sci 29: E508-E514.

Small MF (1990) Alloparental behavior in Barbary macaques, Macaca sylvanus. Anim Behav 39:297-306.

Stewart FA, Piel AK, O`Malley RC (2012) Responses of chimpanzees to a recently dead community member at Gombe National Park, Tanzania. Am J Primatol $74: 1-7$

Sugiyama Y, Kurita H, Matsui T, Kimoto S, Shimomura T (2009) Carrying of 

117:113-119.

400

401

402

403

404

405

406

407

408

409

410

411

412

413

414

415

416

417

418

419

420

421

Van Lavieren E, Wich S (2010) Decline of the endangered Barbary macaque Macaca sylvanus in the cedar forest of the Middle Atlas Mountains, Morocco. Oryx 44: 133 138.

Warren Y, Williamson (2004) Transport of dead infant mountain gorillas by mothers and unrelated females. Zoo Biol 23: 375-378.

Young C, Majolo B, Schülke O, Ostner J (2014) Male social bonds and rank predict supporter selection in cooperative aggression in wild Barbary macaques. Anim Behav 95:23-32.

\section{FIGURES}

Figure 1: RG inspecting the wound of (a) and grooming (b) the mortally wounded MA $(27 / 09 / 13)$

3

14 Figure 2: CA (adult male) takes corpse of juvenile male into tree (centre of picture) (19/05/14).

17 Figure 3: Photograph showing group members following the corpse of the dead juvenile male to an exposed burial site. The monkeys of this group had previously never entered this exposed area. The blue circle highlights the burial site, the red circles highlight group members (19/05/14). 